\title{
Optimization of Rotary Kiln in Cement Industry Using Conventional Control Systems
}

\author{
${ }^{1}$ N. Merrin Prasanna, ${ }^{2}$ Polaiah Bojja \\ ${ }^{1}$ Research Scholar, ${ }^{2}$ Professor, \\ ${ }^{1,2}$ Department of Electronics \& Communication Engineering, Koneru Lakshmaiah Education Foundation, \\ Vaddeswaram, Guntur, Andhra Pradesh, India - 522502 \\ Email: nagadasari.merrin@gmail.com,paulraj.bojja@gmail.com
}

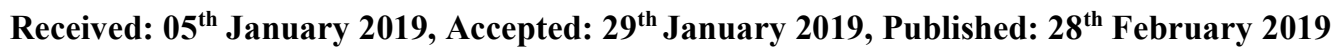

\begin{abstract}
The main aim of the work is used to develop the mathematical models which are used to design conventional control system for the real time cement plant to control several variables of a cement rotary kiln in the plant. A cement rotary kiln is a non linear distributed process which has a highly complex dynamic behavior due to chemical reaction, development of a system to understand the behavior of a kiln process as mathematical model based on control scheme for cement rotary kiln processes. However, the variables are back-end temperature, pre heater temperature, oxygen content and $\mathrm{CO} 2$ gas content of the kiln are used to develop the model of the processes by the most use of Automation. The proposed controller uses a PI controller and PID controller. Finally the designed of Controller scheme for cement rotary kiln process of results are carried out by MATLAB software for evaluation of the performance kiln process.
\end{abstract}

\section{Keywords}

Chemical Reactions, Conventional Controllers, Mathematical Model, Rotary Kiln Cement Process

\section{Introduction}

Control framework hypothesis is considered as one of the imperative and valuable territories in the field of engineering and innovation. With a specific end goal to plan successful controllers for a nonlinear framework, a precise numerical model is required to register the ideal control law. Endeavors to utilize finish numerical models have made the traditional methods burdensomely confused. The diminished request models give an appealing option handy advantage. This casing work is adequate from powerful plan points of view in light of the fact that the mistake limits can be found and the confused flow can be utilized as a part of the amalgamation of strong control laws. The presence and elaboration of exact models is a subject of concern in light of the fact that an extensive variety of marvels can't be incorporated and mapped by the subsequent differential conditions created. Indeed, some of the time basic presumptions are thought to be substantial. What's more, parameters of dynamic frame- works are shifting, and depiction of genuine frameworks by utilizing ostensible models is a doubtful suspicion. Thus the architect can't hope to accomplish a correct streamlining. Robust control is arranged towards the decreased request plan point of view, binds together various wanted goals from heartiness angles, and increases one towards attainable viewpoints in amalgamation, execution, and strength investigation of dynamic frame- works within the sight of limited vulnerabilities.

Distinctive methods have been connected to assault the model diminishment issue. As of late, real improvements in demonstrate lessening have been accomplished, and solid strategies have been distributed.

Hence the substitute technique for managing high- arrange frameworks is to diminish them to a lower ar- range with fitting attributes of the first frameworks. This is done routinely by each control build with occupation to achieve control framework plans, in view of the second request estimate to whatever request the procedure to be and these controls frameworks work, typically calm well. There are different circumstances, anyway for which a second request show isn't sufficient and where an orderly, expository way to deal with advancement of an estimate would be attractive.

Along these lines by lessening the request of the frame- work we accomplish the accompanying:

1. Ease in physical development of the model,

2. Less computational many-sided quality

3. Models of less size and at lower cost and

4. Lower dimensional "control law" (K).

Process in Rotary Kiln:

The process involved in the cement rotary kiln is the Heating Process. Figure demonstrates the structure of a turning furnace with the most imperative factors utilized for control purposes simplified. The oven is a long and complex passage, for the most part with a barrel shaped shape. The heap, constituted by material pieces that have been shaped and incompletely dried, is presented at one of the closures and conveyed along the oven at a low speed. The info materials are incorporated of carbonates and silicates which ought to be singed to create strong oxides and ignition gases. Consuming procedure, meant to all exercises which are done on the crude materials up to make the last clinker, is done in three spots, as takes after: Preheater

1) Kiln

2) Cooler 


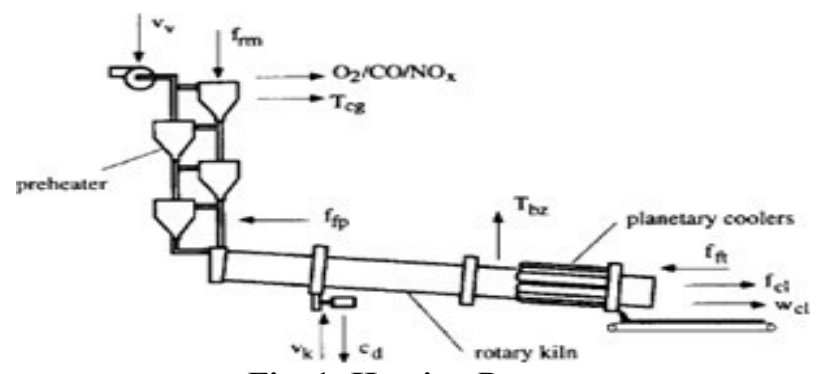

Fig. 1: Heating Process

Crude meal must be preheated and totally gone away before it is bolstered into the oven. Hot smokes created in the oven amid the clinker generation are utilized. Pre-radiator is mindful to secure the remained dampness of the crude material and separate silicates, and also calcinate mostly the present carbonates in the material.

The fundamental piece of the consuming activity is finished by the furnace. The materials heated in two place of the furnace. To begin with heating is happened at the back-end and the second is done at the consuming zone. The back - end is in charge of calcification the materials previously the principle heating. On the off chance that the temperature of the back - end be more than the lawful range, it causes that the support has been done soon before to enter the consuming zone. Then again, the low back-end temperature causes a fragmented support of the materials.

The concrete oven is an enormous barrel shaped pas- sage which the sizes of its length and distance across have an immediate corresponding to the industrial facility limit. By and large, the length and distance across of a concrete furnace is 60 and 4 meters, individually. The chamber, with a precarious around 4 percent, turns around its pivot and the crude feast clean adheres adhesively to its dividers. There it step by step gets singed and heated to create clinker, coarse-grained bits of bond which are then transported far from the furnace and processed in an uncommon plant, to get the concrete clean. The barrel is marginally disposed down its hub from the crude meal fill end to the clinker yield end. Along these lines, the crude dinner and in this manner the clinker gradually slip towards the chamber yield. Suction fans are introduced close to the pre-warmer which cause entering the air from the opposite end of the oven. This has an impact on the fire bearing and the course introduction of ignition gases. On this side of the oven, a fire has been introduced to give the required temperature over the tempera- ture $1400{ }^{\circ} \mathrm{C}$. Likewise, an auxiliary air is constrained from this side of the passage, i.e. in counter-present. This air, which expands the oxygen substance of the furnace, has been as of now warmed in the cooling procedure done on the yield clinker. Truth be told, the stream estimation of the information air is spoken to as optional pneumatic force. In the interim, close to the center of the oven is the terminating zone, where gas burners are put to force the given temperature profile. Calcification is the main activity done on the crude factory at the oven by such high temperature. The high temperature at the consuming zone dissolves the info materials. At that point, primary consuming is bit by bit begun and synthetic responses are done amongst silicates and the present oxygen of the air. CO gas incorporates the principle part of the ignition smokes. At long last, the concrete gems are made and go out from the oven as the clinker.

The yield clinker has a temperature from 1000 to $1200{ }^{\circ} \mathrm{C}$ and it ought to be cooled toward the finish of the furnace to be exchanged. Cooling the clinker perfectly affects its quality too. The procedure necessities are stringent in an assortment of warm handling frameworks, for example, in concrete making, lime- stone calcining, recuperation of lime in mash plants, and the burning of squanders to give some examples. The burner framework is a vital and a fundamental component. Safety contemplations, straightforwardness and adaptability of task, item quality, vitality productivity, upkeep costs, and the natural effect of the results of ignition are probably the most basic regions that an oven administrator must assess in choosing a furnace burner. In most turning oven application fuel is infused specifically toward the finish of the furnace. The burner is the place the fuel is infused, atomized and touched off. The fuel is blended with air previously or in the burner. The burner positions a fire in such a way, to the point that nonstop start is proficient. The f faltering temperature is factors of fuel compose, fuel/air proportion, and other consuming conditions.

Burner fire geometry (or fire shape) is likewise essential on account of the way that it can change the temperature profile or where the warmth is engaged. To accomplish the ideal fire shape and the most effective ignition conceivable, the rate of blending of both the fuel and burning air through the burner is required. Numerous components can go into burner outline. This can incorporate speeds and how much air is required. Each unique fuel offers its own difficulties. Every burner is intended for the given fuel and application. Extra worries, in the burner configuration, have been made over the item particle of NOx, Sox and different emanations. Less exorbitant powers frequently require more vitality to get ready and consume. These parameters must be completely comprehended while choosing the fuel write, getting ready expenses or ascertaining efficiencies.

The primary objective of the furnace control is creating excellent clinker. Then again, an ideal control of the consuming zone temperature is a standout amongst the most imperative elements for the nature of the clinker. Tragically, the genuine information of this piece of the furnace was not accessible and we compulsorily utilized the accessible information of the back-end temperature of the oven as opposed to the consuming one.

In order to produce high quality of the clinker, we must have desired temperatures and this can be achieved by controlling the pfister. Let us discuss the detailed information about the pfister. 
Chemical Reaction in Kiln Process: The sub- stance responses that happen in the lack of hydration and calcination zones are endothermic, implying that a constant contribution of vitality to every one of the particles of the crude blend is required to finish the response. At the point when the crude blend is heaped up inside a standard rotating oven, the rate of response is constrained by the rate at which warmth can be moved into a substantial mass of particles. To make this procedure more productive, suspension preheaters are utilized as a part of present day bond plants to supplant the cooler upper end of the revolving oven. Crude blend is nourished in at the best, while hot gas from the furnace radiator enters at the base. As the hot gas moves upward it makes coursing "tornados" that different the blend particles as they settle down from above. This significantly builds the rate of warming, enabling individual particles of crude blend to be dried out and in part calcined inside a time of not as much as a moment. On the other hand, a portion of the fuel can be singed straightforwardly inside the preheater to give significantly additionally warming to the suspended particles. The territory of the preheater where fuel is singed is known as a precalciner. With a precalciner, the particles are almost totally calcined as they enter the turning oven. Preheaters and precalciners save money on fuel and increment the rate at which the blend can be traveled through the rotating furnace.

\section{Mathematical Model of Rotary Process: According to Heat Balance Equation:}

With a specific end goal to dissect the furnace frame- work thermodynamically, following suppositions are made:

1. Relentless state working conditions.

2. The adjustment in the encompassing temperature is ignored.

3. Icy air spillage into the framework is immaterial.

4. Crude material and coal syntheses don't change.

5. $\quad$ Arrived at the midpoint of oven surface temperatures don't change.

6. Feed rate of crude material and coal are considered as steady.

Since the majority of the warmth misfortune sources have been considered, there is just a $397 \mathrm{~kJ} / \mathrm{kg}$ - clinker of vitality distinction from the info warm. This distinction is almost $12 \%$ of the aggregate info vitality and can be ascribed to the presumptions and nature of information. The conveyance of warmth misfortunes to the individual parts displays sensibly.

\section{Diffusive Mixing of Granular Materials}

Diffusion was described by Hogg et al (1966) and Cahn \&Fuerstenau (1967) to conform to the one dimensional form of Fick's second law of diffusion which states that the diffusion mixing process is completely random, similar to the diffusion process in liquids or gases and is given by: $\partial \mathrm{c}(\mathrm{x}, \mathrm{t}) / \partial \mathrm{t}=\partial\left(_{\textrm{DD}} \operatorname{Diff} \partial \mathrm{c}(\mathrm{x}, \mathrm{t}) \partial \mathrm{x}\right) / \partial \mathrm{x}$

Where $C(x, t)$ is the concentration at any time, $t$, and distance, $x$, from the original surface and $\ominus$ Diffis the diffusion coefficient. The solution to Fick's second law was presented by Hoggetal (1966) and can be used to predict the relative concentrations of a mixture at any point and any time.

\section{Heat Transfer Paths b/n Particles}

Warmth exchange between strong particles has been depicted by Yagi and Kunii (1957) and Kunii and Smith (1960). Figure 2.8 shows the distinctive ways of warmth exchange between particles. Warmth exchange way 1 is the conduction warm ex- change between the particles through the purposes of contact between the particles. Way 2 is the warmth ex- change by conduction and convection through the liquid film close to the place of contact. Warmth exchange way 3 is the net radiation warm exchange from the surface of a hot molecule to the surface of frosty molecule. Radiation from the hot molecule to the void space amongst particles and radiation from the void space to the frosty molecule are portrayed as ways 4 and 5, separately. Ultimately way 6 depicts the warmth exchange from the surface of the chilly molecule into the heft of the colder molecule because of conduction. The aggregate warmth exchange through each of the six way/s, Q, to the icy molecule can be portrayed as:

$$
\mathrm{Q}=\mathrm{UA} \Delta \mathrm{T}
$$

Where $\mathrm{U}$ is the general warmth trade coefficient, An is the glow trade locale of the atom and $\Delta \mathrm{T}$ is the temperature differentiate between the particles. Consider total heat transfer equation and concentration,

$$
\begin{aligned}
& \partial \mathrm{c}(\mathrm{x}, \mathrm{t}) / \partial \mathrm{t}=\partial(\operatorname{mdiff} \partial \mathrm{c}(\mathrm{x}, \mathrm{t}) / \partial \mathrm{t}) / \partial \mathrm{t} \\
& \mathrm{Q}=\mathrm{UA} \Delta \mathrm{T}
\end{aligned}
$$

Total heat transfer from rotary kiln is directly proportional to the input materials concentration(such as feed rate of raw mill, fuel feed rate for pre-calcinations, fuel feed at the twyer and feed rate of clinker).

$$
\text { i.e., } c(x, t)=Q(Q=U A \Delta T)
$$

Where, $\partial \mathrm{c}(\mathrm{x}, \mathrm{t}) / \partial \mathrm{t}=$ Concentration at any time $\mathrm{t}$ and distance $\mathrm{x}$

$\mathrm{Q}=$ Total Heat Transfer through all paths $\mathrm{U}=$ Overall heat transfer co efficient

$\mathrm{A}=$ Heat transfer area

$\Delta \mathrm{T}=$ Temperature Difference between particles Đdiff $=$ Diffusion co-efficient

trm $=$ Feed rate of raw mill

$\mathrm{ffp}=$ fuel feed rate for pre-calcinations $\mathrm{ftt}=$ fuel feed at the twyer $\mathrm{f}_{\mathrm{cl}}=$ feed rate of clinker

From equations (1), (2) and (3),

$$
\begin{aligned}
& \partial \mathrm{Q} / \partial \mathrm{t}=\partial(\text { Đdiff } \partial \mathrm{Q} / \partial \mathrm{t}) / \partial \mathrm{t} \\
& \partial \mathrm{Q} / \partial \mathrm{t}=\partial(\text { mdiff } \partial(\operatorname{trm}+\mathrm{ffp}+\mathrm{fft}) / \partial \mathrm{t}) / \partial \mathrm{t}
\end{aligned}
$$




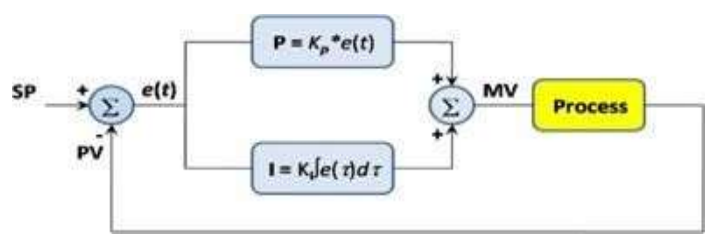

PID Controller in Rotary Kiln Process:

Fig. 2: Block Diagram of PI Controller

PID controller demonstrates the qualities of the every one of corresponding (P), the basic (I), and the subordinate (D) controls, and how to utilize them to get a covet- ed reaction. In this, we will consider the accompanying solidarity criticism framework:

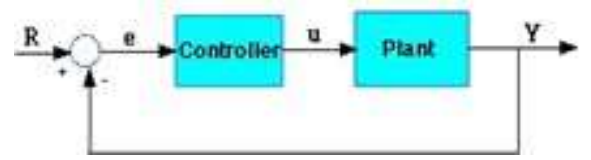

Fig. 3: Block Diagram of PID Controller

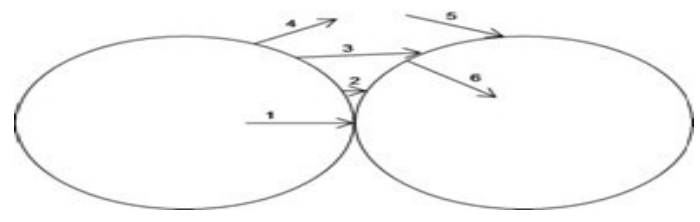

Fig.4: Heat Transfer Paths between Particles (Yagi \& Kunii, 1957).

\section{Controllers used in Rotary Kiln Process:}

In the rotary kiln process the temperature of it is to be controlled and uses a two controllers. They are

1) PI controller

2) PID controller

\section{PI Controller in Rotary Kiln Process:}

The blend of corresponding and fundamental terms is essential to expand the speed of the reaction and furthermore to dispose of the enduring state mistake. In this, we will consider the accompanying solidarity input framework: Plant: A framework to be controlled i.e., rotational oven Controller: Provides the excitation for the plant; De- signed to control the general framework conduct

\section{The Three-Term Controller}

The Transfer function of the PID controller resembles the accompanying:

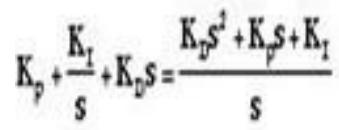

$\mathrm{Kp}=$ Proportional gain $\mathrm{KI}=$ Integral gain $\mathrm{Kd}=$ Derivative gain

To start with, we should investigate how the PID controller functions in a shut circle framework utilizing the schematic appeared previously. The variable (e) speaks to the following blunder, the contrast between the coveted information esteem(R) and the genuine yield (Y). This mistake flag (e) will be sent to the PID controller, and the controller processes both the subsidiary and the fundamental of this blunder flag. The flag (u) simply past the controller is currently equivalent to the corresponding addition $(\mathrm{Kp})$ times the greatness of the mistake in addition to the necessary pick up (Ki) times the vital of the blunder in addition to the subordinate pick up (Kd) times the subsidiary of the blunder.

$$
u=K_{p} e+K_{r} \int e d t+K_{v} \frac{d e}{d t}
$$

This signal (u) will be sent to the plant, and the new yield (Y) will be gotten. This new yield (Y) will be sent back to the sensor again to locate the new mistake flag (e).

The controller takes this new blunder flag and figures its subsidiary and its vital once more. This procedure continues forever.

The Characteristics of P, I, And D Controllers:

A relative controller $(\mathrm{Kp})$ will have the impact of lessening the ascent time and will diminish, however never wipe out, the enduring state blunder. A necessary control (Ki) will have the impact of wiping out the enduring state mistake, yet it might exacerbate the transient reaction. A subsidiary control $(\mathrm{Kd})$ will have the impact of expanding the strength of the framework, decreasing the overshoot, and enhancing the transient reaction. Impacts of every one of controllers $\mathrm{Kp}, \mathrm{Kd}$, and $\mathrm{Ki}$ on a shut circle framework are condensed in the table demonstrated as follows. 


\begin{tabular}{|l|l|l|l|l|}
\hline CL RESPONSE & RISE TIME & OVER- SHOOT & SETTLING TIME & S-S ERROR \\
\hline Kp & Decrease & Increase & Small Change & Decrease \\
\hline Ki & Decrease & Increase & Increase & Eliminate \\
\hline Kd & Small Change & Decrease & Decrease & Small Change \\
\hline
\end{tabular}

\section{Software Used}

MATLAB (network research facility) is a multi- worldview numerical processing condition and fourth- age programming dialect. Created by Math Works, MATLAB permits network controls, plotting of capacities and information, execution of calculations, making of UIs, and interfacing with programs written in different dialects, including $\mathrm{C}, \mathrm{C}++$, Java, Fortran and Python.

\section{Design of the Controller for Rotary Kiln Process:}

The implementation of controller for rotary kiln process is to improve performance and to get the quality of cement.

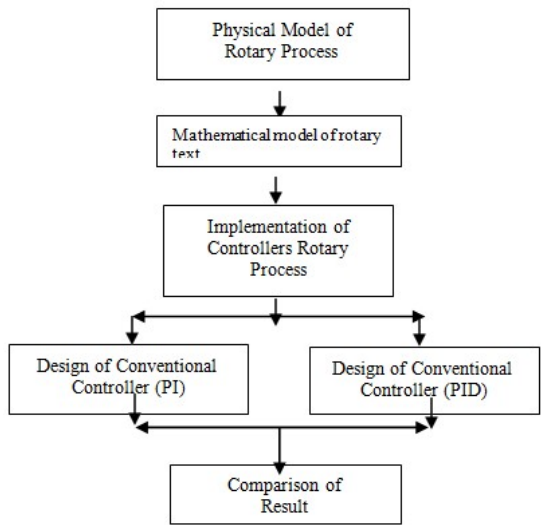

Fig. 5: Flow Diagram for Design of Controller for Kiln Process

The above figure shows the design of the conventional and non conventional controller based mathematical model of cement rotary kiln process and is explained as follows

Physical Model of Rotary Process:

Physical model of any framework empowers you to de- liver models that can be effectively reused and imparted to others. Bringing in information and models from different situations guarantees the exactness of the models. The physical model of the rotary process is the rotary kiln consists of 6 cyclones and their temperatures are as follows: Cyclone 1:297 deg

Cyclone 2: $427 \mathrm{deg}$

Cyclone 3: $536 \mathrm{deg}$

Cyclone 4: $713 \mathrm{deg}$

Cyclone 5: $836 \mathrm{deg}$

Cyclone 6: $945 \mathrm{deg}$

The temperature in the kiln ranges from $1055 \mathrm{deg}$ to $1250 \mathrm{deg}$. The flow rate of the raw feed into the kiln is 360 tons/hour. The rotational kiln speed is about 4.70rpm.Here in order to maintain the desired temperatures we have to control the fuel rate and the fuel used here is coal. The fuel rate is controlled by using pfrister.The output of the kiln known as clinkers are cooled by placing coolers (756rpm) so that temperature reduces to $90 \mathrm{deg}$.

\section{Results}

Here the results are carried out with the help of MATLAB software and the response for the process is as follows:

Case 1: When the step input is given and there is no controller the response is as follows:

\begin{tabular}{|c|c|c|}
\hline Parameters & PI & PID \\
\hline Peak-overshoot & 1650 & 1600 \\
\hline Rise time & 8 & 5 \\
\hline Settling time & 78 & 65 \\
\hline Error & 0.2 & 0.002 \\
\hline
\end{tabular}

Table 1: Comparison of the PI and PID Controller

From the above comparison we can conclude that all the parameters are maximum in PI Controller than in PID Controller. Thus, PID Controller is used in the process.

A cement rotary kiln is a nonlinear distributed process which has a highly complex dynamic behavior due to the chemical reactions. The control of temperature in cement rotary kiln for the quality product will be obtained by controller. The implementation of control system, as an advanced control option for the kilns, is intended to minimize the operator interaction in the control process. Therefore, automatic controller, is the use of various control systems for operating the temperatures in the cement rotary kiln processes. Some processes have been completely automated to get the quality of the cement product. Hence, its concluded PID controller has small overshoot, and fast 
response comparing with PI controller based on the implementation of controller for kiln processes.

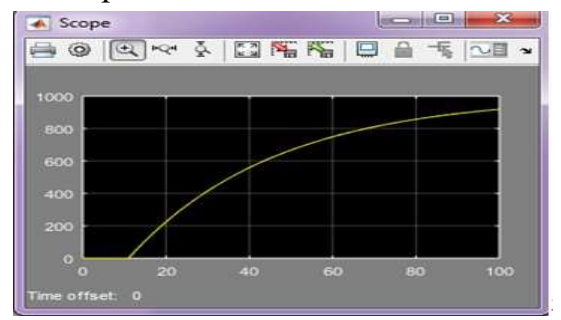

Fig. 6: Response of PID Controller

Case 2: When the step input is given and the PI controller is applied then the response of the process is as follows:

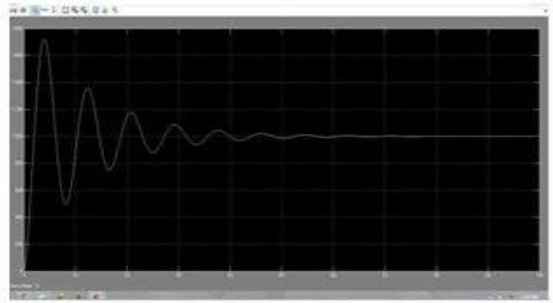

Fig. 7: Response without a Controller

Case 3: When the step input is given and the PID controller is applied then the response is as follows.

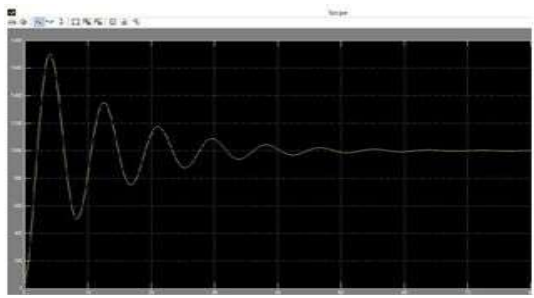

\section{Conclusion}

Fig. 8: Response of PID Controller

The stable operation of kiln precalciner is one of the critical issues in a cement plant and the automatic operation is highly preferred. Due to the complexity of the processes involved, an analytical modeling is extremely difficult as well as to utilize such model for control purposes. In this study a simplified dynamic model between the temperature in precalciner outlet and feed rate of the primary fuel is presented using a series of equal connected tanks. The model with the optimum number of tanks providing the minimal residual errors is used to tune a PID controller between process and control variables. In parallel, several loop properties, like Peak-overshoot, Rise time, Settling time, Error have been computed. The uncertainty of their values is computed based on the uncertainty of the dynamic parameters. The control of temperature in cement rotary kiln for the quality product will be obtained by controller successfully. Due to its simplicity, the tuning results could be used at least as initial PID values in real process. A more precise parameterization needs a more detailed and accurate modeling. . Hence, its concluded PID controller has small overshoot, and fast response comparing with PI controller based on the implementation of controller for kiln processes.

\section{References}

[1] Y. Bo, L. Yi y Q. Shouning, «A rule-based cement kiln control system using neural net- works,» Process. Syst., p. 493-497, 1997.

[2] G. Feng, L. Bin, H. Xiaochen y G. Peng, «Re- search on the fuzzy predictive control for cal- cining temperature of the rotary cement kiln,» de IEEE 10th Int. Conf. SIGNAL Process. Proc., pp. 2568-2571, , 2010.

[3] Z. Li, «Design of fuzzy neural network based control system for cement rotary kiln,» Infor- matics Control. Autom. Robot. , p. 290-293, 2010

[4] S. Wang, F. Dong y D. Yuan, «The Design and Implementation of a Cement kiln Expert Sys- tem,» de In 2007 IEEE International Conference on Automation and Logistics, Jian, China, 2007.

[5] Z. Li, «Support Vector Machine Model Based Predictive PID Control System for Cement Ro- tary Kiln,» de Control and Decision Conference (CCDC), 2010 Chinese, Xuzhou ,2010.

[6] O. Hernández, P. Ortiz y J. Herrera, «Cement Rotary Kiln Model Using Fractional Identifica- tion,» IEEE América Latina, vol. $12, \mathrm{n}^{\circ} 2$, pp. 87-92, 2014.

[7] H. Bode, «Relations between attenuation and phase in feedback amplifier design,» Bell Syst. Tech. J. , vol. 19, pp. 421-454, 1940.

[8] S. Manabe, «The non-integer integral and its application to control systems,» Japanese Inst. Electr. Eng. J. , vol. 6, n $3-4$, p. 8387, 1961.

[9] A.Oustaloup, La Commade CRONE: Com- mande Robuste d'Ordre Non Entier, Hermes, 1991. 
[10]Oustaloup, F. Levron y F. Nanot, Frequency band complex non integer differentiator : char- acterization and synthesis,» IEEE Trans. Cir- cuits Syst. I Fundam. Theory Appl., , vol. 47, nº 1, p. 25-40, 2000.

[11]Podlubny, «Fractional-order systems and PI $\lambda$ D $\mu$ controllers,» IEEE Trans. Automat. Contr., vol. 44, p. 208-214, 1999.

[12]P. A. Iglesias, Control Systems Design, The Johns Hopkins University, 2000. [13] A. Tep- ljakov, E. Petlenkov y J. Belikov, «FOMCON : Fractional-Order Modeling and Control Toolbox for MATLAB,» A J. Theory Ordered Sets Its Appl., vol. 4, 2011. 